\title{
Dimensions of Trust in Scholarly Communication: Problematizing Peer Review in the Aftermath of John Bohannon's "Sting" in Science
}

\author{
Jutta Haider \\ Information Studies, Department of Arts and Cultural Sciences, Lund University, \\ SE-22100 Lund, Sweden. E-mail: jutta.haider@kultur.lu.se \\ Fredrik Åström \\ Lund University Library, SE-22100 Lund, Sweden. E-mail: fredrik.astrom@ub.lu.se
}

This study investigates online material published in reaction to a Science Magazine report showing the absence of peer-review and editorial processes in a set of fee-charging open access journals in biology. Quantitative and qualitative textual analyses are combined to map conceptual relations in these reactions, and to explore how understandings of scholarly communication and publishing relate to specific conceptualizations of science and of the hedging of scientific knowledge. A discussion of the connection of trust and scientific knowledge and of the role of peer review for establishing and communicating this connection provides for the theoretical and topical framing. Special attention is paid to the pervasiveness of digital technologies in formal scholarly communication processes. Three dimensions of trust are traced in the material analyzed: (a) trust through personal experience and informal knowledge, (b) trust through organized, internal control, (c) trust through form. The article concludes by discussing how certain understandings of the conditions for trust in science are challenged by perceptions of possibilities for deceit in digital environments.

\section{Introduction}

On October 4th, 2013 Science Magazine published an article by science journalist John Bohannon. In it he exposed the shortcomings of the peer-review and editorial practices of a set of open access journals. The article, tellingly titled "Who's afraid of peer review?" (Bohannon,

Received February 13, 2015; revised September 24, 2015; accepted September 24, 2015

(c) 2016 ASIS\&T • Published online 00 Month 2016 in Wiley Online Library (wileyonlinelibrary.com). DOI: 10.1002/jasist.23669
2013), reports on an experiment not unlike the by-now famous Sokal's Hoax (Sokal, 1996). Bohannon submitted a deliberately flawed research article under an invented author name and with a made-up university affiliation to 304 fee-charging, open access journals in biology. The article was based on invented results with obvious errors both in terms of language and concerning the reporting of methodology and results. Still, slightly more than half of those journals accepted the submission and proceeded to publish the article. What had happened can only be explained with a seriously flawed peer-review process or an absence of one, despite the stated claims of the journals to have established peer-review processes for assessing submissions.

Not surprisingly, as both press and social media picked up on the issue, emotions ran high. Criticism of open access journals, their weak or nonexistent peer-review processes, and the entire open access model were harsh. Yet criticism of Bohannon's study itself, "The Sting," as it is now called, was harsher still. For many, it was less an issue related to open access, but pointed to problems with formal scholarly communication and how we use it to uphold trust in science as our foremost knowledge-producing institution. The present article is an analysis of reactions to Bohannon's study "The Sting" in Science Magazine as they appeared online shortly after the "The Sting" itself was published. These make for a unique case for analyzing perceptions of the processes fundamental to the assessment of academic research and science and of how these relate to the challenges posed by current large-scale technical and societal trends that have emerged with the pervasiveness of Internetbased, digital technologies in today's society. Specifically, they refocus the issue of trust in the formal scholarly literature and can be seen as pointers towards the grounds for 
questioning the mechanisms and assumptions on which this trust is built.

\section{Aim and Motivation}

This article aims to make visible some of the ways in which notions of formal scholarly communication relate to certain conceptualizations of science, of the hedging of scientific knowledge, and of how trust is a part in upholding these relations.

The article takes account of two current trends that have implications for science and research and hence for scholarly communication processes. These are, first, the pervasiveness of Internet-based, digital technologies in most aspects of society, including academic culture and research practices, and second, the increasing acceleration and competitiveness of academic research, an increasing pressure on scholars that is often captured in the well-known dictum "publish or perish." The latter is not least connected to the development of a culture of evaluation; where various publication numbers and impact factors are among the quantifiable variables drawn on to establish how funds should be distributed and how professional academic careers should develop (cf. Musselin, 2013; Müller, 2014). Both trends are also reflected in demands from major research funding bodies to make published research openly available online, so-called open access mandates.

Central questions in this context are: To what extent does Bohannon's article reflect problems associated with open access journals or problems with the peer-review process per se; and in an extension of this, which processes are essential for trust in the formal scholarly communication system and by proxy trust in science and academia more generally? In which ways are the workings of these processes envisioned as being complicit in creating and upholding trust? And what happens when the institutions and processes that are seen as responsible for distribution and control of research and those who create it are being challenged? These broader issues are addressed through a combination of quantitative and qualitative textual analyses of responses to Bohannon's "The Sting" as they appeared online in the 2 weeks following its publication.

\section{Outline of the Article}

In the next part the material is theoretically and topically situated in order to frame an understanding of the larger context in which "The Sting" took place. After discussing open access and some recent changes in scholarly publishing, the relations between trust, knowledge, and the scholarly journal in the light of digitization are explored. A discussion of the role and meaning of peer review in scholarly publishing concludes this part of the article. Subsequently, method and material selection are presented. The results are discussed in two sections: Dimensions of Critique, combining qualitative and quantitative analyses to describe the overall themes identified in the reactions on Bohannon's article, and
Dimensions of Trust, where we focus on different aspects of trust in the scholarly communication system. In the concluding section the theoretical themes are drawn together with the empirical investigation.

\section{Background}

\section{Changes in Scholarly Publishing and Open Access}

The new information infrastructures made possible by the ubiquity and pervasiveness of Internet-based, digital technologies have altered scholarly communication and publishing (Borgman, 2007). Almost all parts of formal scholarly communication-from access to the literature to communication with and between editors and peer-reviewers to publishing and archiving-have moved online. The border between formal and informal scholarly communication has become increasingly blurred, with social media and new networking platforms specifically for the academic community now widely available. Citations to and from articles have become easy to track in simple interfaces such as those offered by general-purpose commercial search engines.

The publication process has developed into an increasingly fragmented system. On the one hand, articles are about communicating results and on the other hand they are about conveying status and affiliation (Frohmann, 2004). What's more, research publications are important currency in a growing culture of evaluation, a development that further complicates their status and role. Empirical evidence suggests that-across all disciplines-researchers are being pulled in different directions and that this has implications for their communication practices (Fry et al., 2009). Each way of looking at scholarly publications implies different demands for how the publishing system and the mechanisms supporting it work.

The costs associated with making research public online are now negligible and in theory self-publishing by researchers would be feasible. Yet while this has led to the role of scholarly publishers being challenged, their central role is far from being dismissed. The publishing of scholarly journals is now concentrated in the hands of a small number of commercial publishers (McCabe, 2002; Roosendaal, Zalewska-Kurek, Geurts, \& Hilf 2010, p. 56-59). At the same time the question of how and in which form research financed by the public should be accessible to the public has developed into a much-discussed issue. It started out as a concern mainly addressed by researchers who wanted to retain intellectual property and control over their own publications and by research libraries, who found it more and more difficult to deal with the constantly increasing subscription fees for scholarly journals (Haider, 2008). From starting out as an alternative movement spearheaded by librarians and a handful of particularly committed researchers, open access has now acquired an established status. Today the discussion has entered the mainstream. Many research funders, including some of the world's largest ones, for instance, the National Institutes of Health (NIH), the Research Councils in the UK, and the Wellcome Trust, 
demand that publications based on research funded by them are made available in some form of open access; and more and more national policies demand open access to publicly funded research.

Making the results of scientific and other forms of academic research available through open access publishing is to a high extent motivated by the argument that results of publicly financed, quality-controlled research should be made openly available, without restrictions imposed by expensive subscription fees, for all to use: from small biotech start-up companies without access to libraries or enough of a budget for subscription fees, to university libraries in Third World countries with limited funds. Typically, two ways towards achieving this are discussed: by parallel publishing of articles published in traditional journals in open archives or repositories-also called "green open access"or by publishing in journals with open access and no subscription fees. The latter model goes by the name "gold open access." A common business model for open access journals - especially in the life sciences - is for the journals to charge article processing charges (APC) - fees paid by the authors of the article to cover costs related to the publication process. The idea is to finance the publication process through those financing, performing, and communicating research, rather than those "consuming" and using the results of research (Suber, 2012).

Attempts at making research literature freely available either in repositories or in open access journals with or without APCs is not without controversy. Often, traditional journal publishers have seen open access as a threat to their profit margins. Yet with open access gaining ground in policy-making and research-funding agencies increasingly mandating open access, by now virtually all major traditional publishers have launched their own open access or hybrid journals as part of their business models. Still, open access continues to be a heterogeneous phenomenon. While open access today has acquired mainstream status in many contexts, over the last 20 years it has frequently come under attack (e.g., Biello, 2007) and some of the animosities that started then live on in current debates. Obviously, the interests of various stakeholders, for instance, scholars, funders, publishers, libraries, industries, and all kinds of lobby organizations representing those groups, and which meet around open access, pull in different directions.

Interestingly, despite the fact that open access appears as uncontroversial in research policymaking and even traditional scholarly publishing houses have adapted to it, it continues to have an image problem with many researchers. For many there is confusion regarding the difference between open access journals and repositories and especially concerning the role of peer review in open access (Fry et al., 2011). As a recent study has shown, many researchers still have quite negative associations with open access, connecting it to poor peer review or the absence thereof, newly started and less respectable journals, or some other downsides associated with the model (Nicholas et al., 2014). Most of these ideas are grounded in misconceptions (ibid., p.129), yet they continue to contribute to the questionable image open access has for some. And as not least "The Sting" goes to show, there does in fact exist a breed of open access journals that appear to be pure moneymaking ventures and do not act according to any established rules for how scholarly publishing is supposed to be carried out. For instance, they often lack or provide inadequate information on where the publishing company is located, who the editors are, or who is on the editorial board. They also tend to promise excessively fast peer-review processes while being marketed through online spam; this also has to be seen in the wake of demands on scholars from research funding organizations to make their research openly available, where quick publishing in open access journals claiming to have a fast peerreview process could appear as a viable option for some.

Open access of today has become a part of the business portfolio for academic publishers. However, it has always been, and continues to be, more than a business model. The roots of open access are found in a movement with a critical attitude towards making a profit from the records of science and research. As such, open access is assigned different roles in different contexts. A lot depends on whether it is publishers, librarians, university administration, policy makers, or scholarly associations that have to relate to open access. This in itself opens up conflicts and disputes and with it partisan positioning. However, while the focus on open access is interesting and brings with it a particular set of issues, a way of talking, and not least a group of returning persons/ institutions speaking for or against different open access models, all these skirmishes also say something about the state of science and research more generally, which is also part of the setting for this study. It is this murky blend of misconception, the dubious practices of some Internet gold diggers, science policy and the conditions for carrying out research, of traditional publishers' business models and profit margins, and a passionately driven movement that makes the arena Bohannon's "Sting" stepped into. This is also the background for our article.

\section{Trust, Knowledge, and the Scholarly Journal}

Knowledge and trust are intertwined, as Hardwig (1991) developed at length in his seminal article. Most of what we can know we cannot know through experiencing it. We rely on the judgment of others to know and frequently knowledge is mediated; it comes to us not only through other people, a dimension captured in the notion of interpersonal trust, but also through institutions, tools, and documents. The latter forms are often subsumed under the notion of institutional trust. (cf. Hardin, 2002; Simon, 2013) Intricate, multilayered systems are put in place to be able to trust in order to know, learn, and function as a society. Science itself is one such system and within science various interdependent methods are employed to ensure it is seen to work successfully as a trust-creating and trust-maintaining institution. Thus, a series of mechanisms and bodies work together to assure the establishment of trust and of stabilizing 
knowledge. Central in this endeavor are institutions such as universities, research funders, conferences, publishers, and not to forget the scholarly journal with its editorial processes and peer review (Bornmann, 2011; Cronin, 2005).

As described by Shapin, "knowledge is a collective good" and in order to be able to trust knowledge we have to able to trust others (Shapin, 1994, p. xxv). In addition, increasingly we also need to trust advanced technical systems, not least the web and the various organizations and algorithms that make it work. Simon (2010) outlines what she calls the entanglement of trust and knowledge on the web as a sociotechnical epistemic system by drawing on accounts of how trust is established in science. The web, as Simon convincingly argues, can be understood as analogous to science, with both functioning along similar principles. Both are, she argues, sociotechnical epistemic systems where we need to trust others in order to be able to know (Simon, 2010). Yet while Simon teases the web and science apart, in order to help us understand one with the other and in this way highlights a number of valid issues, for the study at hand we need to complicate the relation of science and the web. Contemporary research practices and especially those to do with the literature (writing, publishing, researching, searching, referencing, and reading) are thoroughly digital and in themselves entirely dependent on the web. They hinge on various digital tools almost every step of the way (Sundin, 2014; Woelert, 2013). Hence, in addition to understanding the web and science as analogous sociotechnical systems driven by their entanglement of trust and knowledge, they also need to be understood as systems that are entangled with each other.

Scholarly journals have for a long time been one of the most important institutions to communicate research results and status as well as to establish the value of research. They go back to the 1600 s and the very early journals that were founded then; most notably, Philosophical Transactions of the Royal Society and Journal des Sçavans. There exists a close connection between science, its peer review, and the scholarly journal, which was established then and which continues to be influential even in contemporary discourse. This is also reflected in a recent study on "Trust and Authority in Scholarly Communications in the Light of the Digital Transition," which showed that, at least from the point of view of researchers, a high level of trust is attributed to the scholarly journal even today (University of Tennessee \& CIBER Research, 2013) and it is peer review that is the key proxy for this trust. The next section discusses the role of peer review in scholarly publishing, and specifically how it is thought to contribute to establishing trust.

\section{Peer Review and the Recent Changes in Scholarly Publishing}

Trust and processes to communicate and ground trust are intimately intertwined with what we accept as trustworthy knowledge in science, and through this these processes become part of science. A central part in controlling and assessing researchers, their activities, and their results, is the peer-review system: the process by which researchers' reports of their results in scholarly articles is reviewed by other researchers in order to ensure that research was carried out in a correct manner and that the results are of interest for the science community and worth publishing. The basic idea is that experts from the same area of research judge value and quality of the research contribution prior to publication. In order to ensure fairness, the focus is on scientific criteria only, and to minimize the risk of bias influencing the review process this is typically done with some sort of anonymity involved. Either the review is undertaken single-blind, where the identity of the writer or the reviewer is kept hidden or, which is the most common and best-known procedure, so-called double-blind peer review is used, where neither the identity of the author(s) nor of the reviewer(s) are revealed (Ware \& Monkman, 2008).

Even peer review can look back on a long tradition (Biagioli, 2002; Shapin, 1994), although it has also always been controversial, not least with regard to its definition and extent (Biagioli, 2002). In the beginning, peer review was directly bound to certain persons-so-called gentlemenwhose role as arbitrators of trust was derived from their social status and economic independence (Shapin, 1994) and who reviewed texts of people from exactly the same social background (and of the same sex-male). Over the centuries, and especially during the $20^{\text {th }}$ century, not least connected to the enormous growth of science after WWII (Bornmann \& Mutz, 2014; Larsen \& von Ins, 2010), different processes have developed in order to ensure that people, mechanisms, and systems behind peer review arbitrate trust in ways that correspond better with the ideals of a more meritocratic society and in order to reduce the significance of status derived from values outside the scientific system. Much can be said about how and if this succeeded. However, the main points are, first, even if strategies have changed and the circle of participants has widened considerably, the significance assigned to trust has not decreased; and second, processes of peer review are intimately connected to the society that fosters science as its foremost knowledge-producing institution.

As we discussed earlier in relation to open access, the systems of scholarly publishing and communication have undergone a number of changes in recent decades (Borgman, 2007). First, increased pressure to publish brings with it higher demand for peer review. Since it is essentially the same researchers who publish and review, this further increases the workload. Second, the peer-review process per se has been increasingly debated, and we find a growing amount of studies showing problems related to the process, including bias and nepotism, as well as problems with interrater reliability, in the peer-based assessment of articles, research proposals, and evaluations of research institutions (e.g., Bornmann, 2011; Bornmann et al., 2013; Garcia et al., 2015; Lee et al., 2013; Wennerås \& Wold, 1997). Not only open access, but also subscription-based journals have been forced to retract large numbers of articles (Steen et al., 2013; 
van Noorden, 2014), and even entire journals have turned out to be fake (Grant, 2009). However, since the costs for making material available online are marginal, this has also opened up a discussion of new approaches to carrying out peer review-for example, open peer review, meta review, crowdsourcing peer review (Ford, 2013; Hames, 2012; Yarkoni, 2012)—and thus to address some of the identified shortcomings (Borgman, 2007 p. 60-63).

\section{Studying Reactions to "The Sting": Material Selection and Methodological Issues}

To trace the reactions and comments on Bohannon's article, the Open Access Tracking Project Primary (OATP Primary) was used to identify web documents, which reported and commented on Bohannon's article. OATP Primary is an alert system connected to an e-mail list that collects web documents on issues concerning open access. We went through all posts on the OATP Primary from the day Bohannon's article was published $\left(13^{\text {th }}\right.$ October 2013$)$ and 2 weeks onwards, when the comments and reactions subsided. In all, 81 web pages containing articles or blog posts with comments on Bohannon's article were identified and the URLs to these web pages were saved in a text file for retrieval of the documents and subsequent quantitative and qualitative textual analyses.

\section{Quantitative Analysis}

For the purpose of the quantitative textual analyses, the TextRipper (ToolTextRipper, 2008) tool was used to harvest the text from the web documents. In all, 81 URLs were fed into the TextRipper. Out of the original 81 documents, it was possible to collect information from 78 documents: two were discarded for language reasons, and one for not being a text-based document. In the analyses, separate documents explicitly defined as parts of one longer comment were merged into a single document, leaving us with 76 documents as the basis for the quantitative and qualitative analyses. The harvested text was analyzed using VOSviewer, v. 1.5.4 (van Eck \& Waltman, 2010; VOSviewer, 2014). This is a tool for visualizing the results of bibliometric and text corpus analyses (van Eck \& Waltman, 2011). The text corpus analysis tool identifies noun phrases that are ranked according to relevance and frequency of the phrases, and then analyzed depending on co-occurrences, which is how often different noun phrases appear together in a text. The co-occurrence frequencies are used as proximity measures for the construction of a graphic representation in the form of a map, as well as for cluster analyses bringing related concepts together. This way we get an overview of the concepts in a text or a text collection, as well as how these concepts form different themes in an area; in our case, reactions to Bohannon's article on peer review and open access.

\section{Qualitative Analysis}

The quantitative textual analysis provided us with an overview of the topical areas in the texts that had been published or posted online in reaction to Bohannon's article. To get a more in-depth understanding of these topics, how they emerged and are arranged in the discussions concerning Bohannon's stunt, we also carried out a qualitative textual analysis of the same 76 documents. To explain, the qualitative textual analysis was done informed by the results of the quantitative textual analysis. Dominant topical clusters in the map were used as entry points into the qualitative, thematic textual analysis. In addition to this, attention was paid to how the established topical clusters relate to each other. Each document was numbered, printed out, and coded in an Excel file according to a scheme that had one of the topical clusters as its starting point, yet which developed and branched out organically as the analysis progressed. This required also going back and forth between the individual documents in order to capture and be able to describe the commonalities and differences that materialized during the process of analysis.

\section{Analysis and Results}

Reactions to Bohannon's article appeared in different types of web-based sources (Figure 1). General/general interest media and news outlets - both traditional, such as The Guardian and The Economist, and solely web-based ones such as The Huffington Post, as well as for instance the news pages on the website of National Geographic reported on the article in Science Magazine in the form of news items/ articles. The great majority- $78 \%$ of the documents-however, were reactions coming from websites and blogs with a focus on scientific research and scholarly communication. Most of the reactions from the academic and scholarly communication field came from individual scholars and other people interested in scholarly communication issues, with $36 \%$ of the total. The shares of other involved entities - such as communities and associations, libraries, and commercial scholarly publishers/content providers - are relatively evenly distributed, ranging between $7-11 \%$ of all documents with reactions of Bohannon's article. Many of these, not the least among individuals and communities, are active scholars with an expressed interest in scholarly communication issues as well as open access proponents with strong ties to what can be described as the "OA movement." The great majority of the reactions, especially in documents with an origin in the academic/scholarly communication field, are in the form of blog posts, with the exception of news items, which are the most common form of documents from science news media, and also some more formal comments on websites of associations such as the open access Scholarly Publishers Association (OASPA) and the Scholarly Publishing and Academic Resources Coalition (SPARC).

The results of the analyses can be seen from two different perspectives: On the one hand there is an empirical question of the actual content of the reactions to Bohannon's 


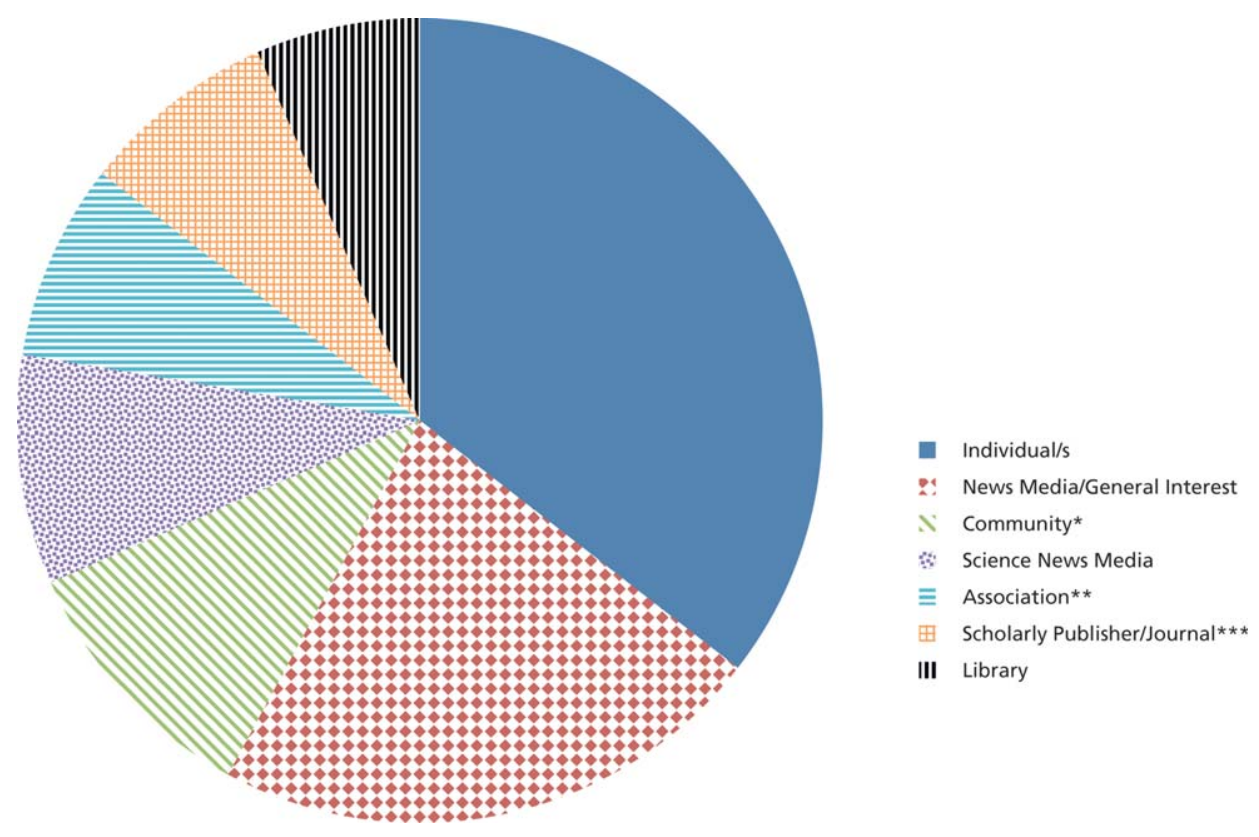

FIG. 1. Type of publishing entities $(n=76)$. *Nonformalized community of interested parties. **Formalized, nonprofit organization. ***Also including other commercial content providers/platforms in the field of scholarly communication. [Color figure can be viewed in the online issue, which is available at wileyonlinelibrary.com.]

article - in this study called dimensions of critique; on the other hand, it also opens up a theoretically grounded discussion of the content to explore different dimensions of trust and of their roles in the scholarly communication process.

\section{Dimensions of Critique}

Bohannon's article attracted attention in different arenas: in academia and academic publishing circles, in the open access movement, as well as in public media, and the reactions were strong and oftentimes emotional. Three sets of issues are broached. One is a critique of the design and execution of Bohannon's study. The other two concern issues regarding the very problems identified by Bohannon in his article: on one level in terms of critique against open access journals and the quality of the peer-review process in those journals; on another level, also a critique against the peerreview process per se, together with concerns related to how scholarly communication processes to an increasing degree also has become a central aspect of research policy and evaluation processes (e.g., open access mandates, the use of bibliometric indicators for assessing academic merit as well as distributing resources and so on). These themes are identifiable as distinct clusters when using VOSviewer to map relations between terms used in the different sources reacting to Bohannon's article (Figure 2).

The most obvious theme in the reactions relates to the issues Bohannon wanted to address, that is, problems with substandard peer-review processes in some open access journals and with predatory open access journal publishers, and to what extent open access publishing processes can be trusted. This theme corresponds to the cluster found on the lower-right side of the map, with concepts related to, on the one hand, quality issues related to peer review and academic publishing, and on the other hand, concepts related to open access publishing (Figure 3). Many of these reactions focus primarily on the issue of predatory publishers within the open access landscape and how journals and publishers who are obvious scams-promising unreasonably fast review processes and claiming to be based in the United States of America while operating out of another-often so-called developing countries - and only interested in money making damage the trust, not only in open access publishing, but also in scientific research and publications in general. There is, however, in these reactions also a discussion concerning the extent to which open access publishing experiences more general problems, and in particular with "gold" open access publishing financed through APCs. The combination of readily available digital technologies for publishing, open access mandates, and the demands on researchers to publish or perish brings out less trustworthy entities who want to make a quick profit from hard-pressed researchers looking for publishing venues. Yet there is also a discussion on how an open access model financed by "pay-to-publish" strategies brings with it the risk of corrupting the publication system in general.

On the lower-left side of the map, there is a cluster with concepts, reflecting criticism against Bohannon's article and the design of the study he based the article on (Figure 4). Regarding the study design, the main objections raised had to do with the fact that the study, in fact a piece of investigative journalism rather than scholarly research, had itself not undergone peer review and moreover that it lacked a control group. That is, critics maintained, the results were not particularly meaningful if they cannot be compared to how 


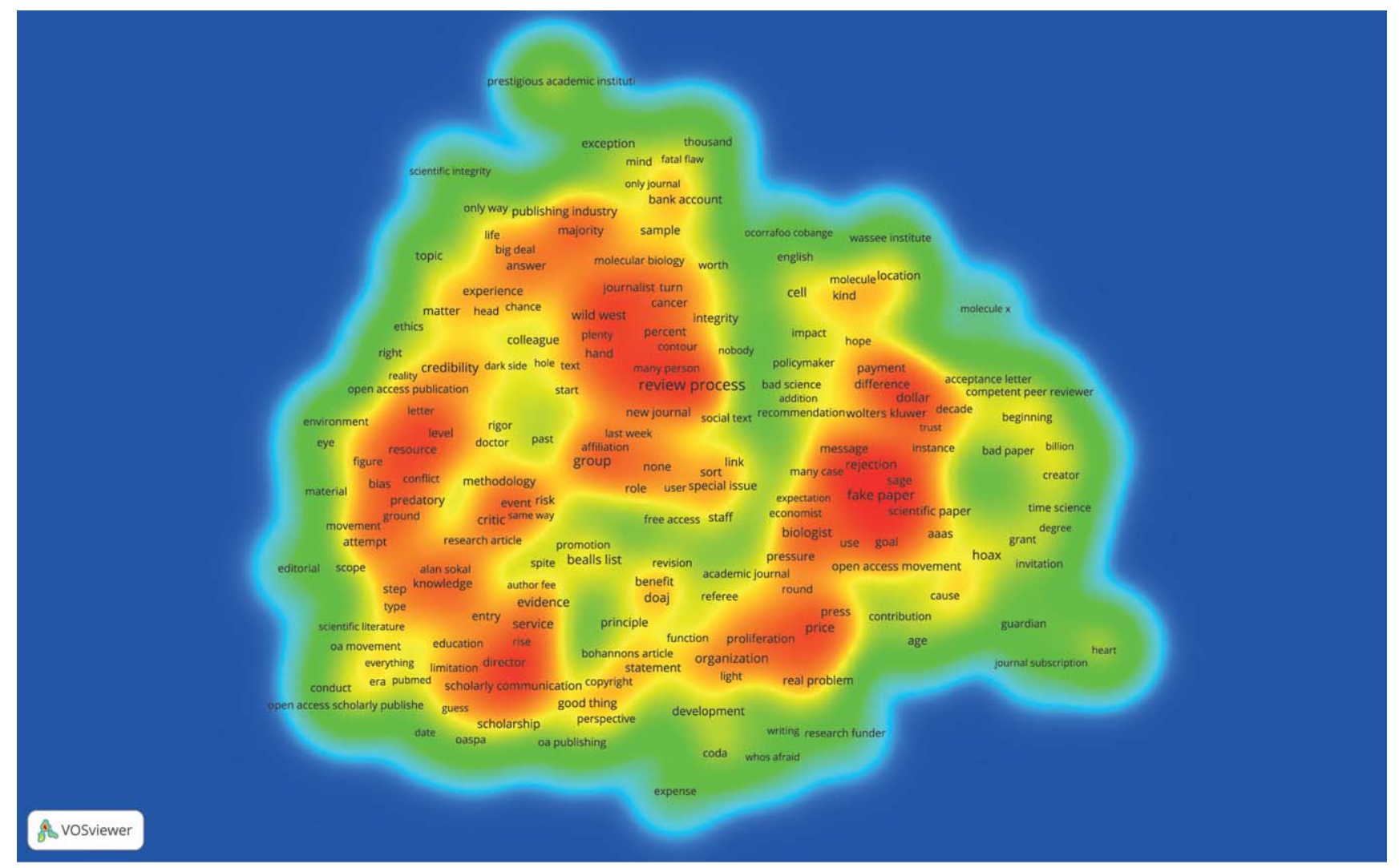

FIG. 2. Conceptual map of web documents reporting and/or commenting on Bohannon's Science article. [Color figure can be viewed in the online issue, which is available at wileyonlinelibrary.com.]

scholarly journals in this field of research in general would have acted in such a situation or what open access journals with no APCs would have done. This makes it impossible to say if the problem identified by Bohannon concerns peerreview or editorial processes in open access journals with APCs, or if it has to do with peer-review and editorial processes in scholarly journals in general. Another issue concerned the selection of the journals to which the flawed article was submitted. Some were chosen from the Directory of Open Access Journals (DOAJ), a well-known source for finding OA journals, but others were selected from Beall's list of predatory publishers (Beall, 2012). This is an often used, but also frequently debated, list of open access journal publishers with a reputation for low-quality publications, low-level quality control, and with the main purpose of making a quick profit preying on scholars pressured to make their research articles openly accessible. Using this list as a basis for selection, the criticism goes, introduced a level of bias.

Having said that, which themes come into focus varies depending on who is commenting. Here the main difference can be seen with regard to where someone stands with regard to open access. More precisely, while advocates of "green open access" tend to focus on problems with APCs, advocates of "gold open access," or for that matter open access advocates with no explicit position regarding gold or green, to an increasing extent focus on problems associated with Bohannon's investigation and the design of his study in the first place.

Embedded in this criticism of how Bohannon's study was designed, executed, and quality-controlled are also further themes that expand on the topics that his study in fact pinpoints as problem areas. These are most notably misconduct in the scholarly publication process, peer review and its challenges, quality assessment and the role of research ethics, as well as to a lesser degree open access itself. In the upper part of the map, there is a cluster of concepts related to publication and peer-review processes in general, that is, problems with, for instance, poor peerreview processes that are not directly linked to open access publishing, but with scholarly publishing in general (Figure 5). To explain, on the surface, most reactions did relate to perceived advantages or disadvantages of the open access model for scholarly communication. Yet this was done in relation to other, broader concerns addressing the configuration of scholarly communication and publishing, research practices, and the communication of research results, more specifically how it is communicated, in which forums, for whom and for which purposes, and most importantly how it is vetted.

To illustrate, "Open access tries to put researchers and funding institutions back in control of scientific dissemination cutting the obnoxious middleman, the scientific journal," (Jariego, 2013) writes a researcher blogger using open 


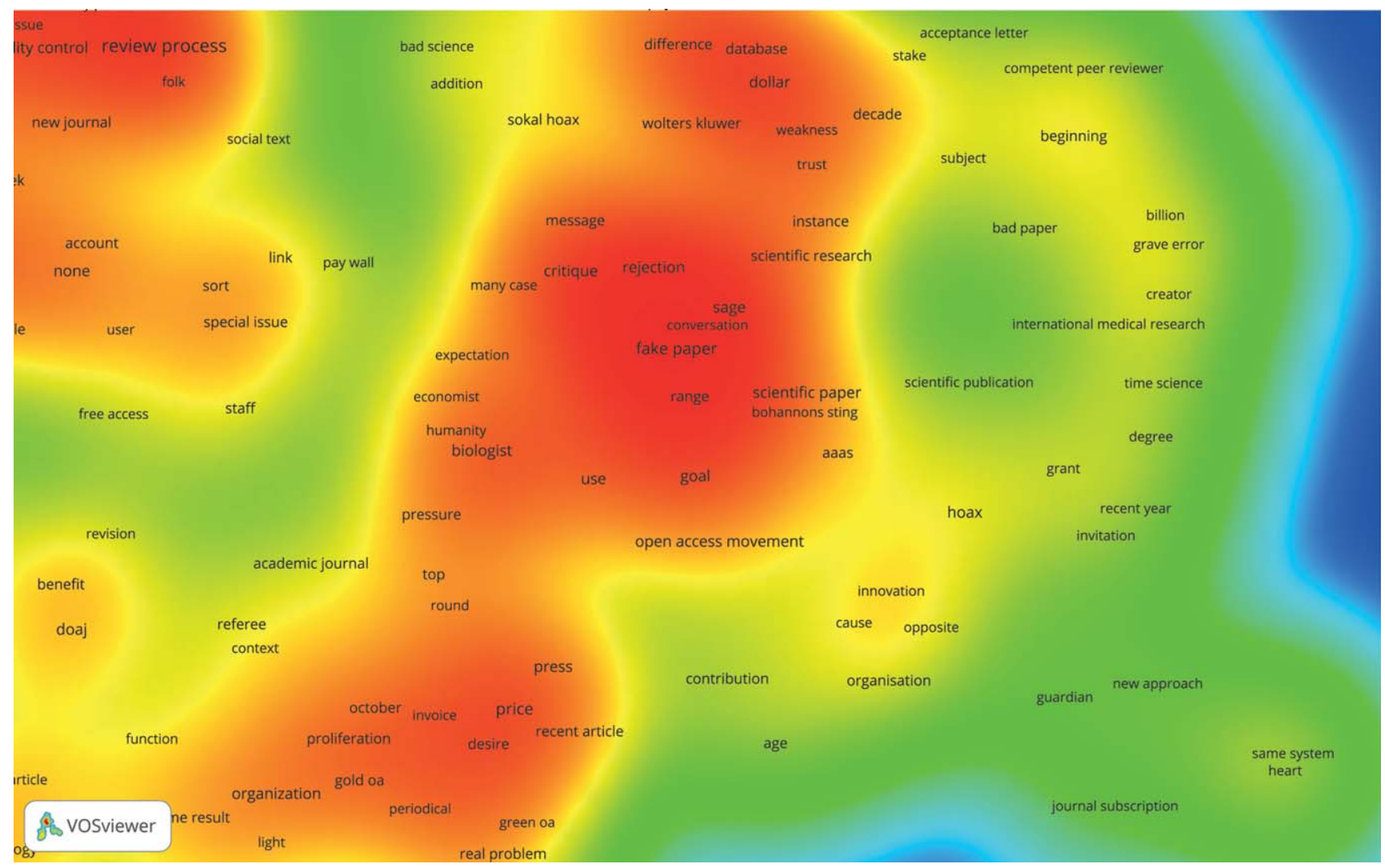

FIG. 3. Reactions on Bohannon's article: Cluster 1, problems with OA publishing. [Color figure can be viewed in the online issue, which is available at wileyonlinelibrary.com.]

access as a proxy for discussing control over scholarly communication more generally. Another researcher blogger expressed the following viewpoint: "There are deep problems with science publishing. But the way to fix this is not to curtain Open Access publishing. It is to fix peer review" (Eisen, 2013). Yet another comment, also on the blog of an individual researcher, reads as follows: "it's about a more general breakdown in the peer review and the ability to evaluate trust but he targets only open access here" (Eve, 2013). While leaning on open access to introduce a position and to distance themselves from Bohannon, a much broader topic is brought into the picture, namely, peer review and not least the difficulties with control and in particular with quality control in research in general. In the last quote above, "trust" is introduced to capture the extent of the problem identified. Considering, as we have discussed earlier, how central trust is for the system of science and how crucial it is that the processes meant to enable it are perceived as doing their job (Cronin 2005; Hardwig, 1991; Shapin, 1994; Simon 2010), introducing "trust" highlights just what is at stake.

In fact, broader issues of trust tied to the publishing process emerged in different ways in the material. Through this, questions have emerged regarding implications of today's highly competitive system in science on scholarly communication and the various editorial processes connected with scholarly publication processes. These implications hint at the uneasy relationship that exists between the two discourses of scholarly communication that we touched upon earlier: a practice discourse, which highlights status and career advancement, and an epistemic discourse which has the communication of the content and the results of a research carried out at its heart (Frohmann, 2004). While trusting the content from the point of view of communicating research between scholars and peers, the scholars reading the texts of their peers can make decisions themselves, based on their knowledge of the topic matter and the field per se, as well as their knowledge of those authoring the text. Yet when it comes to the function of an article within a system for merit and reward, the assessment of the text becomes more dependent on formal and organized mechanisms for establishing quality and status of a publication.

Taking this into account, we paid particular attention to how trust itself is written about, but considered also concepts such as credibility, quality, control, ethics, conduct, or misconduct that were used in relation to peer-review processes as well as to science and research in general to address issues of trust.

\section{Dimensions of Trust}

On a general level we could trace three significant dimensions of trust for how formal scholarly communication is thought of: trust through personal experience and informal 


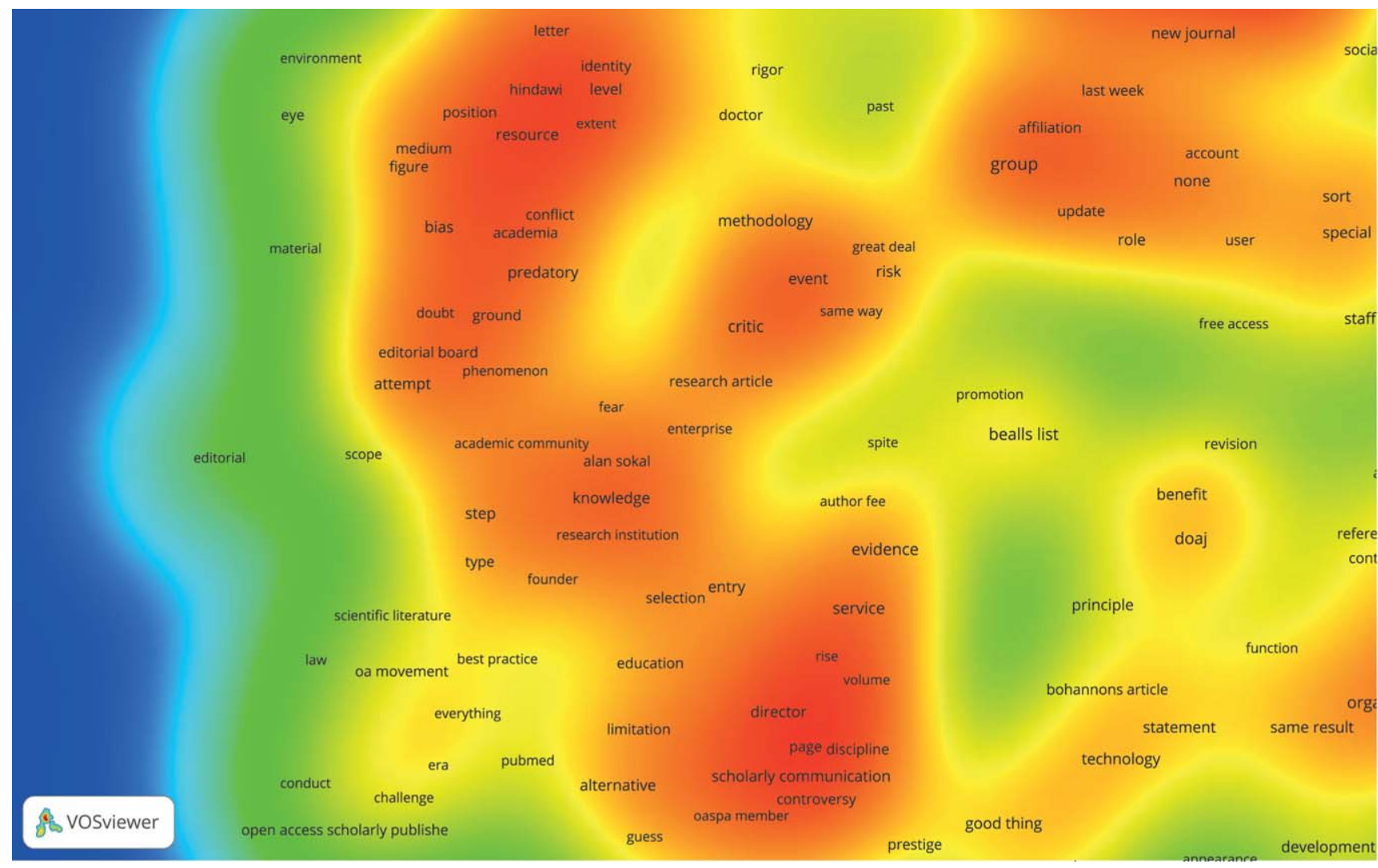

FIG. 4. Reactions on Bohannon's article: Cluster 2, critique of Bohannon's article. [Color figure can be viewed in the online issue, which is available at wileyonlinelibrary.com.]

knowledge, trust through organized, internal control, and trust through form. They differ with regard to how trust is mediated, but also where trust is located in relation to scholarly communication and research in a more general way. Frequently, in accordance with the focus of Bohannon's "Sting," peer review acts as the connector for establishing these relations.

Trust through personal experience. Trust through personal experience derives from trust in known colleagues, at least by name, functioning as gatekeepers, who act as peer reviewers and assess the literature within the system. It also derives from personal experience and in that way it is based on a type of informal knowledge that is part of a community. For instance, on one research blog this is expressed as follows: "I am, of course, only talking about relatively small journals from small academic communities, I know of all of the people on the editorial boards, and have met many of them" (Webster \& Gawne, 2013). Here, the bloggers speak from first-hand experience and bring it in as an illustration of how to establish what counts as a journal to trust within a community. Another commentator, a researcher writing on a community blog, expresses a similar experience in the following way: "scientists aren't stupid; we know good venues, we know how to find them, and we can spot dodgy emails from a mile off" (Shipman, 2013). Here it is not contacts, but personal experience, informal and inferred knowledge on how to judge publishing venues, and how to recognize deceitful adverts.

In our material, the personal experience dimension is the least tangible of the three ways of locating trust. Not unsurprisingly, it is also limited to a certain type of text that voiced reactions to Bohannon's study, namely, blogs of active researchers. Trust is described in terms of trust in colleagues, in known persons. An important aspect of how this plays out is through reference to the personal contact network, where trust is located in known names with commissions of trust in the publishing system, such as editors, editorial boards, or conference committees. Another aspect of personal trust can be found in references to researchers' own ability to accurately assess whether to trust, for instance, a journal or an e-mail, advertising a journal or conference. Hence, trust derives to a large degree from researchers' knowledge of the field they work in together with their ability to assess information about publishing venues with regard to a journal's marketing strategies or who is represented on its editorial board. This chimes well with Nicholas et al.'s (2014, p. 125) finding that personal networks, virtual and physical, are central to how academics establish trust in the literature, for the purpose of publishing as much as for keeping up-to-date and referencing.

However, trust that hinges on personal networks is also vulnerable, especially when a field expands and agents outside established networks need to be assessed. This 


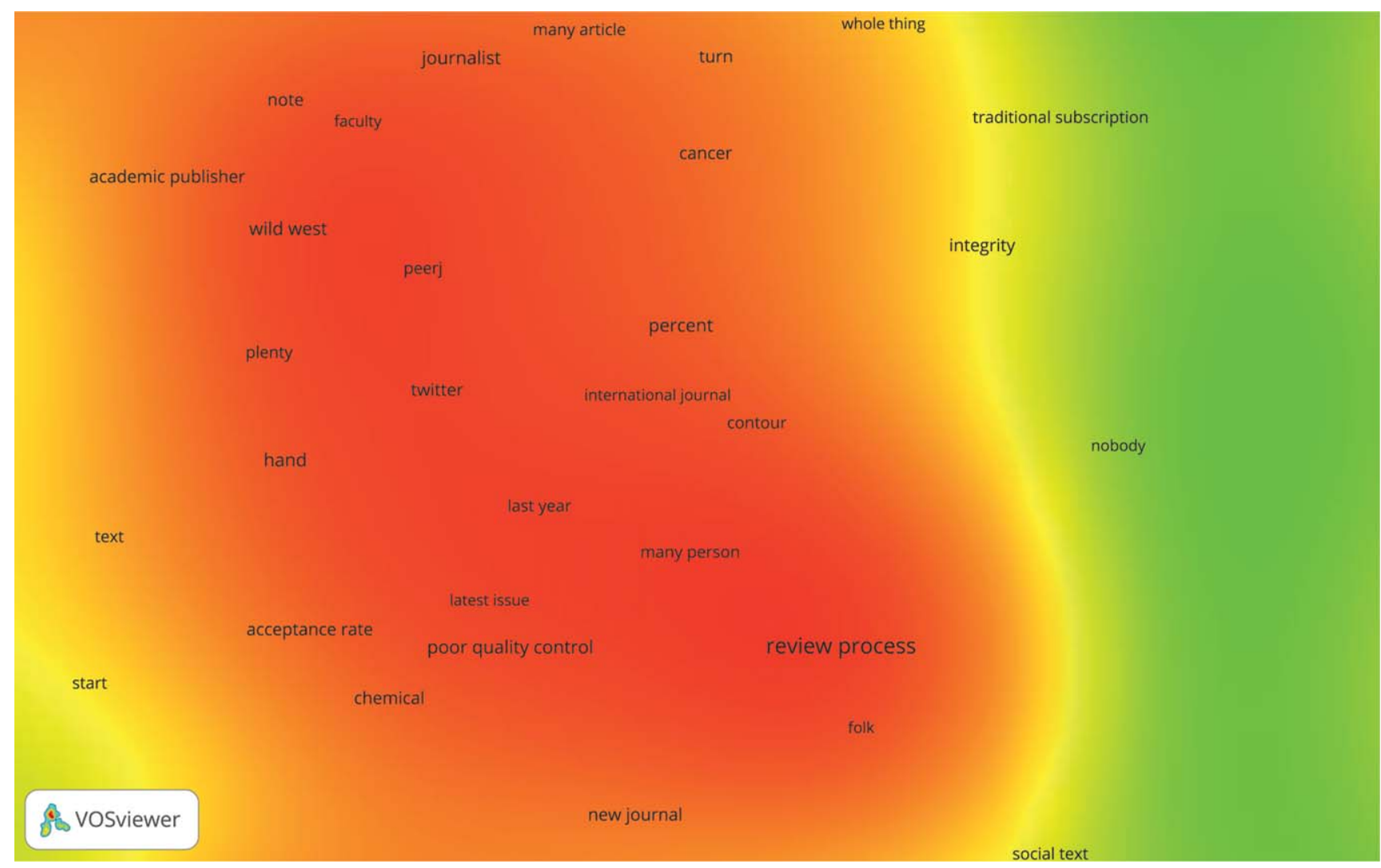

FIG. 5. Reactions on Bohannon's article: Cluster 3, problems with peer review and the scholarly publication process in general. [Color figure can be viewed in the online issue, which is available at wileyonlinelibrary.com.]

dimension can predominantly be traced in forums, which address the general public. Here, whether or not trust in an article or in a journal is deserved is also established by relating it to a periphery of science, that is, as epitomized by journals and researchers from the so-called developing world. This is not incidental, but already a part of "The Sting" as Bohannon had planned and carried it out. Bohannon's alias was an African author affiliated with a made-up African university and many of the journals he submitted to were based in India. This raises questions as to whether Bohannon's study is prejudiced against the so-called developing world or if it possibly intended to expose other's prejudice. It also leads to questions regarding the reliability of journals that claim to be published in the USA while in fact being published in, for instance, India. Most interestingly, however, this confirms that trust in science is constructed in relation to numerous factors supporting each other, including historical, social, cultural, and political ones, and then put in relation to aspects of trust that involve personal knowledge of a field and of colleagues. Both sides conspire in how we judge quality and construct trust in formal scholarly publications, as two sides of the same coin.

Trust through organized, internal control. Another way of situating trust happens in relation to sets of routines and mechanisms that are employed to administer editorial processes and peer review. These are control mechanisms integral to the publication process and, as we have shown earlier, these have traditionally been fundamental to the hedging of scholarly knowledge as closely wedded to the institution of the scholarly journal. As also mentioned before, peer review is the most important feature in this context. Yet, as we know, the relationship between peer review and publications is far from untroubled and this is also what we encountered in our material. To illustrate: "The problem is what we think peer review can accomplish" (Smith, 2013), writes one commentator on a library/scholarly communication blog, while another one expresses the following view:

Quantity versus quality. We are facing the same problem both with scientific papers and patents: low-quality or even fake papers, too broad patents to be used as weapons in an arms race. There is virtually no way to control for the proliferation of junk scientific and technological production. An increased demand for science and technology and the wrong incentives are blowing up the traditional control mechanisms: research peers and patent office budget and clerks. (Jariego, 2013)

In both cases expectations of peer review are assumed to be high, but both also problematize this expectation. While 
the first quote indirectly questions the power that is assigned to peer review, in the second quote we can trace a critique of a culture of evaluation by demanding quantifiable output. Here it is the system's new demands that break its own control mechanisms; hence, what is actually being measured does not tally with what should be there in the first place. The extent of peer-review's significance for science becomes even clearer in the following comment made on a researcher's blog:

More worrying, however, is that while Bohannon and Science may have meant this as an attack on open access, this study could easily be picked up by those who oppose science and scholarship. (Morrison, 2013)

Peer review is part of the very structure of the system of science, yet as such it is also somewhat hidden from the eyes of the general public. Making it visible in all its imperfection could mean endangering the very edifice itself. While the relation between peer review and the record of scientific knowledge is seen as foundational, it is also very precarious and full of potential pitfalls that have to be accepted for the trust-establishing system to work. Taken to extremes, this position could be seen to imply that the general public cannot be trusted to trust a system with known faults.

Trust through form. We analyzed publications that mainly address a general audience, rather than a special interest or professional group, separately. Often these articles were related to media whose identity is not primarily that of an online resource only, but tied to legacy media in some form or another. Even here criticism was voiced with regard to how Bohannon conducted his study. Equally, the attitude towards open access was generally positive and it was often described as presenting a possibility for making taxpayer-financed research available to the public. Even here the peer-review process is linked to trust. Attention is also drawn to systemic mechanisms of control, which support the system of scholarly communication. Interestingly, though, a further facet of systemic trust emerges. Mechanisms of control and the systems surrounding them are not primarily valued for helping to assess the scholarly articles as such, but as criteria for checking formalities and through this to check against a certain form. To explain, scientific publications follow a certain format. They look a certain way; they include formal elements like abstract, keywords, reference, and so forth; they are indexed in familiar databases. Without even having to read a text it is possible to see that it is "scientific."

Despite some examples of the format being challenged and new forms developing in the process, the dominant format remains by and large unchanged. More or less the same formal criteria that were used 50 years ago are applied today. These criteria continue to signal a text's "scientific-ness." However, the availability of digital technology has also made it possible and not least affordable for many to design, publish, and distribute a journal that appears to fulfill all formal criteria without necessarily fulfilling any of the mechanisms behind these criteria, that is, editorial processes or other control mechanisms to vet a journal's quality. As one commentator points out on a researcher's blog, albeit this is a positive example:

Now that a competent student RA can format papers using InDesign, and maintain a journal's WordPress page, Open Access journals can be just as professional as any of the bigger players, often while attracting authors and readers from a wider pool. (Webster \& Gawne, 2013)

Today's scientific journals are, in practice, digital all the way through from production to distribution, use, and preservation, but they continue to remediate a form that developed when they existed in print only (Francke, 2008). Remediating a form also remediates values, meanings, and traditions (Bolter \& Grusin, 2000; Francke, 2008) and this includes expectations of whether or not something can be trusted-not necessarily to contain true knowledge, but rather to be what it appears. This is expressed as follows in a general interest news item:

Science journalists ... rely on the credibility of journals when reporting the news, and though some studies can seem fishy, not many ... can quickly review a study and know when to call it bullshit. (Koebler, 2013)

From an insider perspective a journal that merely mimics the formal criteria of "scientific-ness" is rarely a problem, as we discussed earlier. However, in our material it is described as problematic in relation to how science journalists and the general public are supposed to assess whether to trust a specific scholarly publication. Here, formal criteria are traditionally used to establish exactly that; that is, whether a publication merits trust. For instance, a journalist recommends the following procedures:

One easy test is whether the journal has been indexed by PubMed, the journal abstracting service managed by the NIH.... Another thing you can do is look for the journal's impact factor, which is a measure of the average number of citations made to articles in that journal by articles in other journals. (Cooper, 2013)

At the same time, the Internet together with the pervasiveness of digital tools also make it straightforward to establish a journal's status by consulting tools such as journal registers and indexes of scientific articles. In addition, information on how much and by whom a journal is used and its scientific reputation, as expressed in impact factor and similar measures, are also readily available online.

\section{Peer Review at the Intersection of Trust Through Personal Experience and Trust Through Organized Control}

For many, the peer-review system is increasingly experienced as being out of step with the rest of the scientific 
publication system: not least in relation to the structure of scientific career advancement and the requirement for researchers not just to publish, but to publish in high-impact journals and also to publish a lot. The demands on researchers do not increase because of expectations to increase output, but also because they are increasingly in demand as peer-reviewers of articles submitted to journals and conferences. This points to an interesting contradiction at the intersection of trust through personal experience and trust through organized, internal control. It is possible to judge the quality of an article or a journal based on personal experience and knowledge, yet within the context of career advancement the judgment of a journal's quality is based on impact factors and other types of measures.

Out of tradition, researchers trust the peer-review system as such, and particularly the version that draws on more than one reviewer per paper. At the same time, the question is whether this trust is extended to the individual participants in the system. There are a number of studies that also point to problems with the peer-review system, including journals that are increasingly forced to withdraw already published papers and studies showing huge discrepancies in how different reviewers asses a paper's quality (e.g., Bornmann et al., 2013; van Noorden, 2014). This in tandem with the new challenges that are posed by science's exponential growth and continued acceleration has led to debate on the timeliness of peer review and if it all does what it is meant to do (Squazzoni et al., 2013).

A side effect of anonymous peer review-which is still the most common form of peer review-is also that the authors of the texts that are being reviewed do not have to take a stand whether they trust the reviewers, at least never on an interpersonal level. This also made it possible to move the peer-review system from a society that openly builds on inherited family privilege to one that is predominantly meritocratic and where researchers come from diverse social backgrounds. Yet opening up the review process, while this could, on the one hand, make it more transparent, would on the other hand also mean that the spotlight is on the researcher as a person, hence exposing interpersonal trust relationships, which then have bearing on how we conceive of trust.

Nowadays new ways for changing and opening up the system are being discussed, such as crowdsourcing peer review, open peer review, meta review, or postpublish peer review (Ford, 2013; Hames, 2012; Yarkoni, 2012). These and similar trends are also mentioned in the material we investigated. Interestingly, though, much of the discussion centers on how to increase efficiency, while the ways in which trust also describes relationships between people and groups of people, so central in the early days when it was the gentlemen's privilege, remain hidden. Considering the central role of performance indicators in today's research culture, this focus on efficiency makes sense. This way, fixing peer review together with unblocking the bottleneck, as publishing often is experienced, is a rational solution. Yet it obscures the more difficult issue of whether lack of effi- ciency in publishing actually is the problem that needs to be attended to or if it is a symptom of something else.

\section{Discussion}

Bohannon's (2013) study in Science News brings out relevant aspects to consider in relation to both open access publishing and the peer-review system. Obviously, the design of his study has its problems, as is also highlighted in different ways in the reactions it generated. Not least with regard to issues of trust it is interesting to observe that different perspectives on where trust is located, that is, a trust based on personal experience or organizational — or other externalmechanisms, also leads to conflicting views on how research should be assessed. Yet, which questions are asked in the process regarding how we trust formal scholarly communication processes? Is it our trust in open access journals that is at issue, is Bohannon's article actually about our trust in the peer-review system, or does it concern trust in the system of scientific publishing?

From a narrow perspective, a central theme of the Bohannon article is to what extent open access journals can be trusted: that is the perspective Bohannon chooses, and a substantial part of the reactions and reports following his article also comment on the matter from an open access perspective. There are certainly problems with predatory publishers and journals with poor or nonexistent quality control systems, whose prime motivation seems to be making money of APCs from authors, who need to meet the demands of research councils and mandates to make research openly available. Yet, of course, numerous open access journals with well-functioning peer-review processes, as well as open access journals financed by other means than APCs, exist as well. A central part of the creation of trust in open access journals can be seen in the control mechanisms surrounding the publication process, as well as in the actual form of the journal and its articles per se: We look for certain clues meeting our expectations on how a scientific article should look. And it becomes very conspicuous when these clues are missing, such as a journal not being indexed in well-known databases of scholarly literature, and even more so, when claiming to be indexed in certain databases without being so. However, this also raises the question of what happens when trust based on the well-known elements (personal networks, familiar databases, and so on) is challenged by actors who are not part of - or at least known by-our personal networks. To what extent are our perceptions of what is bonafide research something that is based on us being a part of an "old boys or girls club," where we exclude articles and journals just because they are not part of our established network? For instance, we can see a questioning of publications with bases outside the so-called West, where "Third World" or "developing world" is used synonymously with "less reliable." In a general interest news item, this is expressed in the following way: 
A lot of questionable journals, even though they purported to be American, were actually located in third world countries and were clearly in it for money. (Cooper, 2013)

That something appears to be published in, for instance, the USA and not in a country outside the "West" becomes a part of signaling "scientific-ness," which in itself deserves to be trusted. Inversely, absence of this part of trust becomes a signal for questionable quality.

At the same time as we can identify problems with open access journals with poor or nonexistent review processes, problems with the peer-review system are also well known today. Fake articles have also been published in traditional, subscription-financed journals. For instance, recently the publishers IEEE and Springer were forced to retract about 120 articles when it turned out they were computergenerated nonsense (Oransky, 2014). The peer-review process includes both systemic and personal aspects of trust: We trust those reviewing articles to act dutifully and according to a high standard, and that the articles they recommend for publication are based on correctly performed research. We also trust in systemic functions, such as the use of anonymization of both authors and reviewers, and the use of more than one reviewer, to level out effects of biased or poorly performed individual reviews. In Bohannon's article, and in the reactions it caused, we see an identification of the problems he identified with an overall crisis of the peerreview system. Some even claim that the peer-review process is superfluous: the argument being that researchers are perfectly capable of assessing the quality of an article, and to what extent it is useful for further research, regardless of whether it has passed through a peer-review process or not. From this point of view, it would not be a problem to publish everything without prior assessment and let the researchers then decide on what literature is of a high enough standard to use. However, the scholarly assessment process is intimately associated with the extent to which scholarly publications are considered authoritative. Hence, the assessment of the reliability and authoritativeness of an article is not just a matter of making an article useful for scholars in the same field, but also for others, outside the research field and even outside academia. This requires formalized and broadly accepted practices of trust—such as peer review today, but also editorial processes, indexes, and various formal criteria-to stabilize formal scholarly literature.

\section{Conclusion}

The aim of this study was to investigate how notions of formal scholarly communication relate to certain conceptualizations of science, the hedging of scientific knowledge, how trust is part of upholding these relations, and also, how this in turn relates to the pervasiveness of digital technologies in contemporary scholarly communication processes, as well as the increasing competitiveness and the evaluation culture in current research. These issues were analyzed by investigating the reactions to John Bohannon's (2013) article in Science Magazine, revealing problems with the peerreview process in open access journals. In the reactions, three basic themes could be identified: problems related to open access publishing such as faulty peer-review processes, problems with Bohannon's article and the design of his study, and the wider issue of problems related to the peerreview and scholarly communication processes per se. Within these three themes, three dimensions of the concept of trust can also be identified, as expressed in the reactions and as part of our perception of trust in science and the scholarly communication system. The first is trust through personal experience, how researchers use their own knowledge about their research fields and the communication infrastructure within the field to deem a journal or a call for papers as trustworthy. The second dimension of trust is expressed in the reliance on the organized, internal control; that is, in the quality control processes in the systems of editorial work and peer review. The third dimension is formrelated and establishes trust in a publication by determining, for instance, whether a publication actually has the appearance of a scholarly publication or if it is indexed in relevant databases covering scholarly literature.

In the broadest sense, these issues relate to the extent to which scientific research-as expressed through publications - can be trusted. And what happens to scientific research when the merit and reward systems increase the demands on researchers to publish at an ever-increasing rate. In addition to reports on problems with computer-generated nonsense articles being retracted and journals with substandard or nonexistent review processes, we also see an increase in articles being retracted because the experiments they build upon could not be replicated (Steen et al., 2013). At the same time, research projects are abandoned because the amount of research data are deemed insufficient for publication in a journal of high enough impact or prestige (Rushforth \& de Rijcke, 2014). From a strictly communicative perspective on scholarly publishing, researchers may very well be able to determine the quality of an article, regardless if it has passed through a peer-review process or not, but from the perspective of merit and reward systemsthe undisputed imperative of today's science system, peerreview processes and impact indicators are essential aspects of formal scholarly communication. Also, science and academic research - considered as the prime contributors of knowledge in our society-and the scholarly literature need to be communicable to a wider audience outside their own field of research, and with some stamp of approval letting the reader know that an article is based on bonafide research. Thereby, the establishment and maintenance of trust becomes an essential part of the set of the governance systems for assessment, production, and distribution of scientific and scholarly knowledge in a digital culture.

These debates, interests, and standpoints are also interesting as projection screens regarding questions of how society values science and academic research and positions scholarly journals as institutions and attributes trust to them 
through their various systems of quality control and gatekeeping, most notably, peer review in its various forms. Today, with Internet-based digital technologies readily available, these systems have become visible and also open to criticism as never before. Traces of this criticism, and the ongoing dialog, are also more readily available, thus material as the one analyzed here can give us a glimpse into a field at this particular moment in time.

\section{Acknowledgments}

This work has partly been done within the DigiTrust project, funded by the Pufendorf Institute for Advanced Studies, Lund University, Sweden; and the Knowledge in a Digital World framework grant, funded by the Swedish Research Council. We thank the anonymous reviewers for valuable comments improving the content of this article. We also thank Katarina Jandér for help with the graphics for the figures.

\section{References}

Beall, J. (2012). Beall's list of predatory publishers. Retrieved from http://scholarlyoa.com/2012/12/06/bealls-list-of-predatory-publishers2013/

Biagioli, M. (2002). From book censorship to academic peer review. Emergences, 12(1), 11-45.

Biello, D. (2007). Open Access to science under attack. Scientific American, January 27, 2007. Retrieved from http://www.scientificamerican. com/article/open-access-to-science-un/

Bohannon, J. (2013). Who's afraid of peer review? Science Magazine, 342(6154), 60-65.

Bolter, R. J., \& Grusin, R. (2000). Remediation: Understanding new media. Cambridge, MA: MIT Press.

Borgman, C. L. (2007). Scholarship in the digital age: Information, infrastructure and the internet. Cambridge, MA: MIT Press.

Bornmann, L. (2011). Scientific peer review. Annual Review of Information Science and Technology, 45(1), 197-245.

Bornmann, L., \& Mutz, R. (2014). Growth rates of modern science: A bibliometric analysis based on the number of publications and cited references. Accepted for publication in Journal of the Association for Information Science and Technology. Retrieved from http://arxiv.org/ abs/1402.4578v3

Bornmann, L., Mutz, R., \& Daniel, H.D. (2013). A reliabilitygeneralization study of journal peer reviews: A multilevel metaanalysis of inter-rater reliability and its determinants. PLoS One, 5(12), e14331.

Cooper, J. (2013). Fake science paper spoofs hundreds of almost fake journals. The Examiner, October 4, 2013. Retrieved from http://www. examiner.com/article/fake-science-paper-spoofs-hundreds-of-almostfake-journals

Cronin, B. (2005). The hand of science: Academic writing and its rewards. Lanham, MD: Scarecrow.

Eisen, M. (2013). I confess, I wrote the Arsenic DNA paper to expose flaws in peer-review at subscription based journals. In: it is NOT junk: A blog about genomes, DNA, evolution, open science, baseball and other important things, October 3, 2013. Retrieved from http:// www.michaeleisen.org/blog/?p=1439

Eve, M.P. (2013). What's “open” got to do with it? In: Dr Martin Paul Eve, October 3, 2013. Retrieved from https://www.martineve.com/ 2013/10/03/whats-open-got-to-do-with-it/

Ford, E. (2013). Defining and characterizing open peer review: A review of the literature. Journal of Scholarly Publishing, 44(4), 311-326. doi: $10.3138 /$ jsp.44-4-001
Francke, H. (2008). (Re)creations of scholarly journals: Document and information architecture in Open Access journals. Borås \& Gothenburg: Department of Library and Information Science/Swedish School of Library and Information Science University College of Borås/ Göteborg University. Retrieved from http://hdl.handle.net/2320/1815)

Frohmann, B. (2004). Deflating information: From science studies to documentation. Toronto, Canada: University of Toronto Press.

Fry, J., Oppenheim, C., Creaser, C., Johnson, W., Summers, M., White S., \& Hartley, D. (2009). Communicating knowledge: How and why researchers publish and disseminate their findings. LISU Report. Loughborough, UK: Loughborough University. Retrieved from http:// www.rin.ac.uk/system/files/attachments/Communicating-knowledgefocus-groups.pdf

Fry, J. Probets, S., Crease, C., Greenwood, H. Spezi, V., \& White, S. (2011). PEER Behavioural Research: Authors and users vis-à-vis journals and repositories. LISU Report. Loughborough, UK: Loughborough University. Retrieved from http://citeseerx.ist.psu.edu/viewdoc/ download?doi=10.1.1.260.16\&rep $=$ rep $1 \&$ type $=$ pdf

Garcia, J.A., Rodriguez-Sánchez, R., \& Fdez-Valdivia, J. (2015) Bias and effort in peer review. Journal of the Association of Information Science and Technology, 66, 2020-2030.

Grant, B. (2009). Elsevier published 6 fake journals. The Scientist, May 7, 2009. Retrieved from http://www.the-scientist.com/?articles.view/ articleNo/27383/title/Elsevier-published-6-fake-journals/

Haider, J. (2008). Open access and closed discourse: The construction of Open Access as a development issue. ( $\mathrm{PhD}$ thesis). City University London. Retrieved from http://lup.lub.lu.se/record/1544653

Hames, I. (2012). Peer review in a rapidly evolving publishing landscape. In R. Campbell, E. Pentz, \& I. Borthwick (Eds.), Academic and professional publishing (pp. 15-52). Cambridge, UK: Chandos.

Hardin, R. (2002). Trust and trustworthiness. New York: Russell Sage Foundation.

Hardwig, J. (1991). The role of trust in knowledge. Journal of Philosophy, 88(12), 693-708.

Jariego, P. (2013). Given enough eyeballs. In: Mind the post, October 10, 2013. Retrieved from http://pacojariego.me/2013/10/13/givenenough-eyeballs/

Koebler, J. (2013). Inside Science Magazine's 'Sting' of Open Access Journals. In: Motherboard, October 4, 2013. Retrieved from http:// motherboard.vice.com/en_uk/blog/inside-science-magazines-sting-ofopen-access-journals-1

Larsen, P. O., \& von Ins, M. (2010). The rate of growth in scientific publication and the decline in coverage provided by Science Citation Index. Scientometrics, 84(3), 575-603.

Lee, C.J., Sugimoto, C.R. Zhang, G., \& Cronin, B. (2013). Bias in peer review. Journal of the Association of Information Science and Technology, 64, 2-17.

McCabe, M.J. (2002). Journal pricing and mergers: A portfolio approach. The American Economic Review, 92(1), 259-269. Retrieved from http://www.jstor.org/stable/3083331

Morrison, H. (2013). Bohannon and Science: Bogus articles and PR spin instead of peer review. In: The Imaginary Journal of Poetic Economics, October 12, 2013. Retrieved from http://poeticeconomics.blogspot.se/2013/10/bohannon-and-science-bogus-articles-and.html

Müller, R. (2014). Postdoctoral life scientists and supervision work in the contemporary university: A case study of changes in the cultural norms of science. Minerva 52(3), 329-349.

Musselin, C. (2013). How peer review empowers the academic profession and university managers: Changes in relationships between the state, universities and the professoriate. Research Policy, 42(5), 11651173.

Nicholas, D., Watkinson, A., Volentine, R., Allard, S., Levine, K., Tenopir, C., \& Herman, E. (2014). Trust and authority in scholarly communications in the light of the digital transition: Setting the scene for a major study. Learned Publishing, 27(2), 121-134.

Oransky, I. (2014). Springer, IEEE withdrawing more than 120 nonsense papers. Retraction Watch, February 24, 2014. Retrieved from http:// 
retractionwatch.com/2014/02/24/springer-ieee-withdrawing-more-than120-nonsense-papers/

Roosendaal, H.E., Zalewska-Kurek, K., Geurts, P.A.T.M., \& Hilf, E.R. (2010). Scientific publishing: From vanity to strategy. Oxford, UK: Chandos.

Rushforth, A., \& de Rijcke, S. (2014). The impact of indicators: The rise of performance indicators and commensuration in Dutch biomedical research. Paper presented at the EU-SPRI Forum Early Career Researcher Conference/2014 INGENIO PhD Days, Valencia, Spain.

Shapin, S. (1994). A social history of truth: Civility and science in seventeenth-century England. Chicago: University of Chicago Press.

Shipman, M. (2013). Peer Review Quality is Independent of Open Access. In: Communication breakdown: Notes from the trenches on science communication, October 13, 2013. Retrieved from http:// www.scilogs.com/communication_breakdown/jon-tennant-oa/

Simon, J. (2010). The entanglement of trust and knowledge on the Web. Ethics and Information Technology, 12(4), 343-355.

Simon, J. (2013). Trust. In: D. Pritchard (Ed.), Oxford bibliographies in philosophy. New York: Oxford University Press. Retrieved from http// www.oxfordbibliographies.com/view/document/obo-9780195396577/obo9780195396577-0157.xm

Smith, K. (2013). The big picture about peer-review. In: Scholarly Communications @ Duke, October 10,2013. Retrieved from http:// blogs.library.duke.edu/scholcomm/2013/10/10/the-big-picture-about-peerreview/

Sokal, A. D. (1996). A physicist experiments with cultural studies. Lingua Franca, 6(4), 62-64.

Squazzoni, F., Bravo, G., \& Takacs, K. (2013). Does incentive provision increase the quality of peer review? An experimental study. Research Policy, 42(1), 287-294.

Steen, R. G., Casadevall, A., \& Fang F. C. (2013). Why has the number of scientific retractions increased? PLoS One, 8(7), e68397.

Suber, P. (2012). Open access. Cambridge, MA: MIT Press. Retrieved from http://mitpress.mit.edu/books/open-access
Sundin, O. (2014). Akademisk vardag på en global referensmarknad [Academic everyday life in a global reference market]. Kulturella Perspektiv, 23(2), 49-58.

ToolTextRipper (2008). Text Ripper. Retrieved from https://wiki.digitalmethods.net/Dmi/ToolTextRipper

University of Tennessee, \& CIBER Research Ltd (2013). Trust and authority in scholarly communications in the light of the digital transition: Final report. Knoxville \& Greenham: University of Tennessee \& CIBER Research. Retrieved from http://ciber-research.eu/download/ 20140115-Trust_Final_Report.pdf

van Eck, N. J., \& Waltman, L. (2010). Software survey: VOSviewer, a computer program for bibliometric mapping. Scientometrics, 84(2), 523-538.

van Eck, N. J., \& Waltman, L. (2011). Text mining and visualization using VOSviewer. ISSI Newsletter, 7(3), 50-54.

van Noorden, R. (2014). Publishers withdraw more than 120 gibberish papers. Nature News, February 24, 2014.

VOSviewer (2014). VOSviewer Version 1.5.4. Retrieved from http:// www.vosviewer.com/

Ware, M., \& Monkman, M. (2008). Peer review in scholarly journals: Perspective of the scholarly community: An international study. Publishing Research Consortium. Retrieved from http://publishingresearchconsortium.com/index.php/prc-documents/prc-research-projects/ 36-peer-review-full-prc-report-final/file

Webster, G. \& Gawne, L. (2013). Open Access Journals certainly aren't all bad. In: Superlingo: For those of us who like and use language, October 11, 2013. Retrieved from http://www.superlinguo.com/post/ 63671671294/open-access-journals-certainly-arent-all-bad

Wennerås, C., \& Wold, A. (1997). Nepotism and sexism in peer review. Nature, 387(6631), 341-343.

Woelert, P. (2013). The "Economy of Memory": publications, citations, and the paradox of effective research governance. Minerva, 51(3), 341-362.

Yarkoni, T. (2012). Designing next-generation platforms for evaluating scientific output: What scientists can learn from the social web. Frontiers in Computational Neuroscience, 6, 72 .

\section{Appendix}

Sources with comments/reactions on John Bohannon's Science Magazine article

\begin{tabular}{|c|c|c|c|}
\hline Doc nr & Title & Source & Url \\
\hline 1 & Gold... for sale & Cristina Costa Blog & $\begin{array}{l}\text { http://knowmansland.com/blog/2013/10/12/gold-for- } \\
\text { sale/ }\end{array}$ \\
\hline 2 & The big picture about peer review & $\begin{array}{l}\text { Scholarly Communications@Duke- } \\
\text { Duke University Library }\end{array}$ & $\begin{array}{l}\text { http://blogs.library.duke.edu/scholcomm/2013/10/10/ } \\
\text { the-big-picture-about-peer-review/ }\end{array}$ \\
\hline 3 & $\begin{array}{l}\text { "Open access spam" and how journals } \\
\text { sell scientific reputation }\end{array}$ & John Hawkes Weblog & $\begin{array}{l}\text { http://johnhawks.net/weblog/topics/metascience/ } \\
\text { journals/open-access-spam-selling-credentials-2013. } \\
\text { html }\end{array}$ \\
\hline 4 & $\begin{array}{l}\text { The Open Access hoax and other } \\
\text { failures of peer review }\end{array}$ & Language Log & $\begin{array}{l}\text { http://tagteam.harvard.edu/hub_feeds/928/feed_items/ } \\
\quad 286824\end{array}$ \\
\hline 5 & $\begin{array}{l}\text { Anti-tutorial: how to design and } \\
\text { execute a really bad studyyes }\end{array}$ & Sauropod Vertebra Picture of the Week & $\begin{array}{l}\text { http://svpow.com/2013/10/07/anti-tutorial-how-to- } \\
\text { design-and-execute-a-really-bad-study/ }\end{array}$ \\
\hline 6 & $\begin{array}{l}\text { This study lacked an appropriate } \\
\text { control group: Two stars }\end{array}$ & Cracking the Enigma Blog & $\begin{array}{l}\text { http://crackingtheenigma.blogspot.se/search/label/open- } \\
\text { science }\end{array}$ \\
\hline 7 & About Science's Open Access "sting” & National Association of Science Writers & $\begin{array}{l}\text { https://www.nasw.org/about-sciences-open-access- } \\
\text { \%E2\%80\%9Csting\%E2\%80\%9D }\end{array}$ \\
\hline 8 & $\begin{array}{l}\text { Open access \& peer review under the } \\
\text { microscope }\end{array}$ & Kresge Physical Sciences Library & $\begin{array}{l}\text { http://krescook.wordpress.com/2013/10/07/open- } \\
\text { access-peer-review-under-the-microscope/ }\end{array}$ \\
\hline 10 & $\begin{array}{l}\text { Open access journals certainly aren't all } \\
\text { bad }\end{array}$ & Superlinguo Blog & $\begin{array}{l}\text { http://www.superlinguo.com/post/63671671294/open- } \\
\text { access-journals-certainly-arent-all-bad }\end{array}$ \\
\hline
\end{tabular}




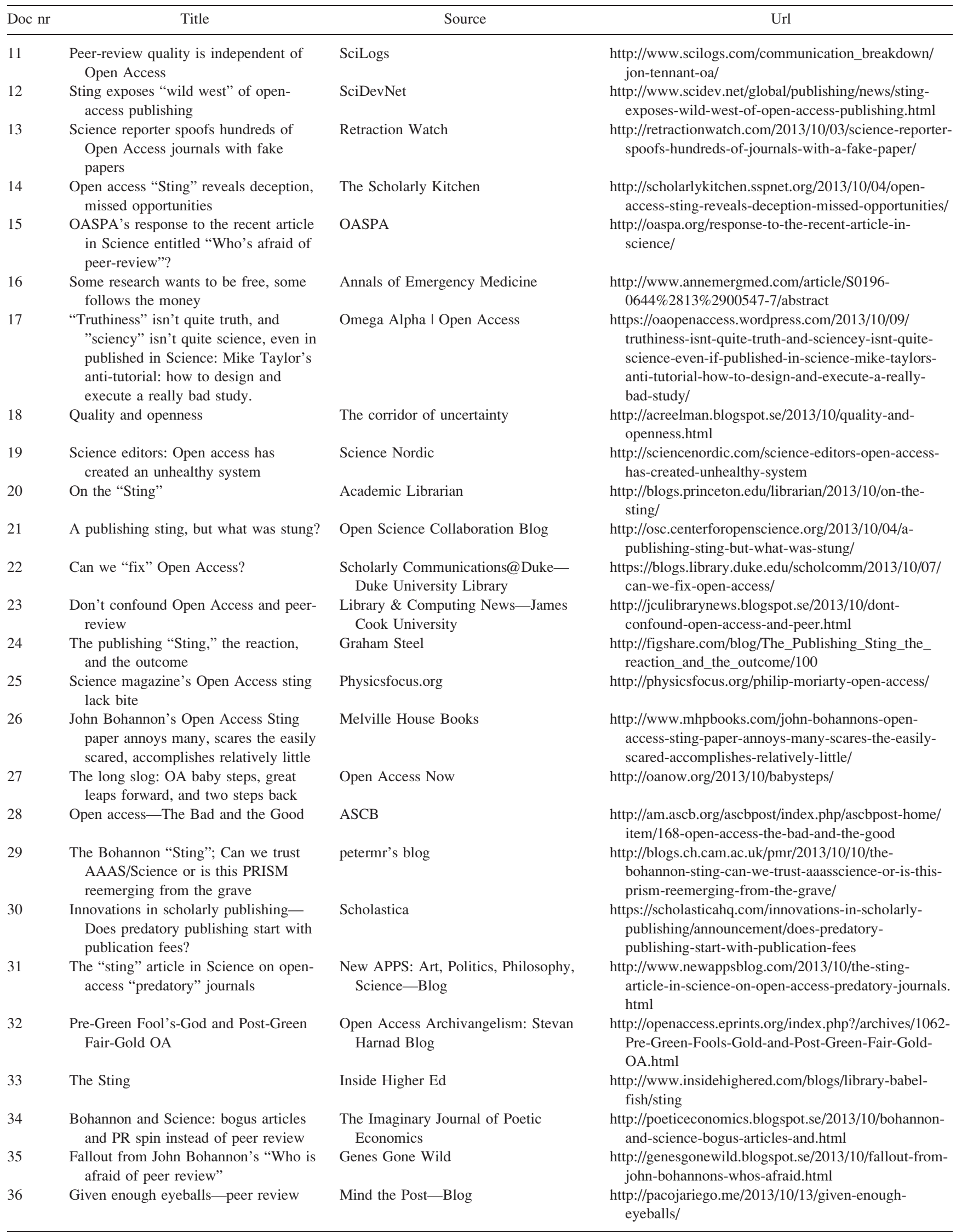




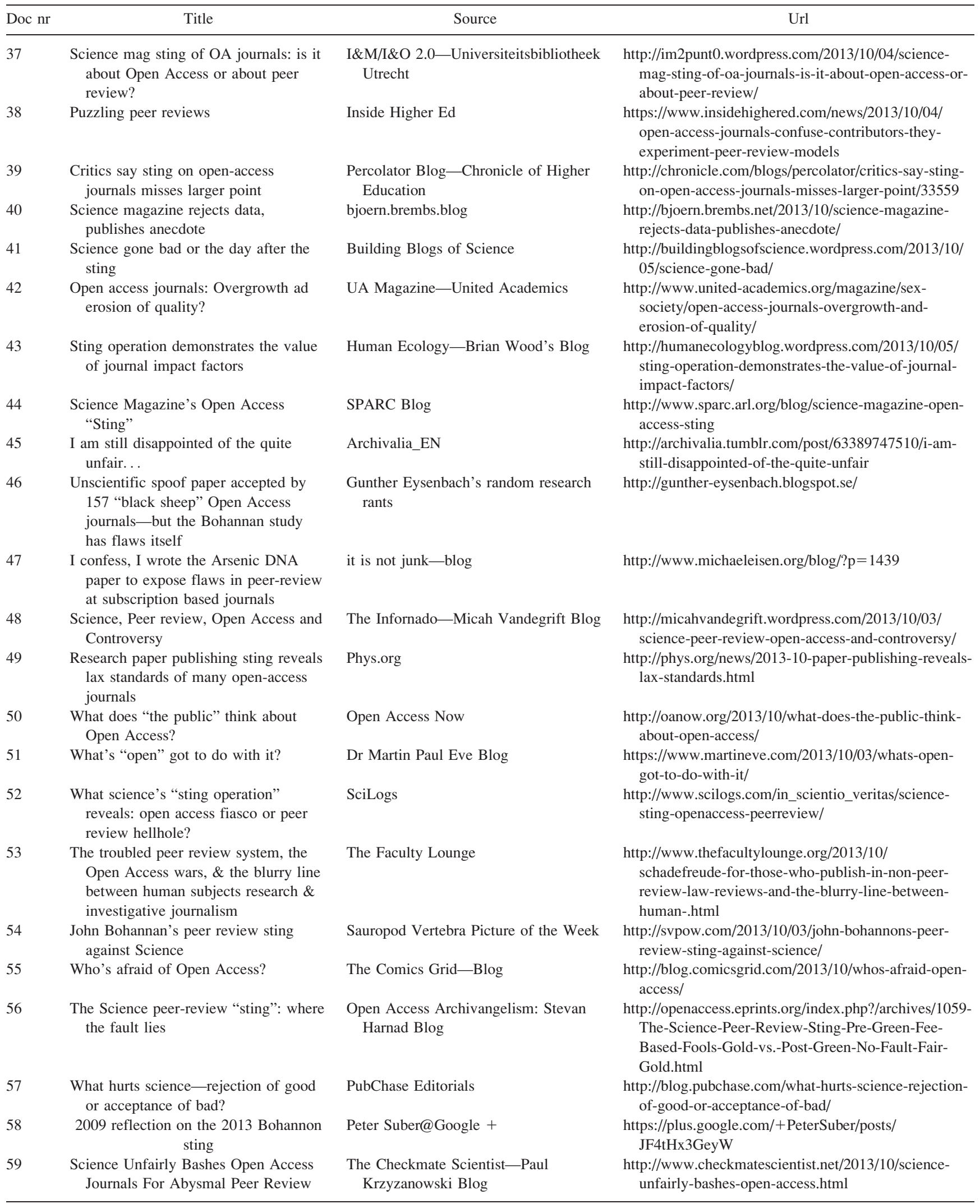




\begin{tabular}{|c|c|c|c|}
\hline Doc nr & Title & Source & Url \\
\hline 60 & Predatory Open Access: Parts 1-3 & Scepticemia & $\begin{array}{l}\text { http://scepticemia.com/2013/10/05/predatory-open- } \\
\text { access-part-1-a-sting-op-and-indictment-of-the-oa- } \\
\text { model/ } \\
\text { http://scepticemia.com/2013/10/06/predatory-open- } \\
\text { access-part-2-peer-review-in-oa-and-ethics-of-sting-op- } \\
\text { research/ } \\
\text { http://scepticemia.com/2013/10/07/predatory-open- } \\
\text { access-part-3-research-spoofs-and-publication-faux- } \\
\text { pas/ }\end{array}$ \\
\hline \multicolumn{4}{|c|}{ News Media \& General Interest Sources } \\
\hline $\mathrm{N} 1$ & $\begin{array}{l}\text { Some online journals will publish fake } \\
\text { science, for a fee }\end{array}$ & UHF News for Houston & $\begin{array}{l}\text { http://app1.kuhf.org/articles/npr228859954-Some- } \\
\text { Online-Journals-Will-Publish-Fake-Science,-For-A- } \\
\text { Fee.html }\end{array}$ \\
\hline N 2 & $\begin{array}{l}\text { Open access publishing hoax: what } \\
\text { Science magazine got wrong }\end{array}$ & The Guardian & $\begin{array}{l}\text { http://www.theguardian.com/higher-education-network/ } \\
\text { blog/2013/oct/04/science-hoax-peer-review-open- } \\
\text { access }\end{array}$ \\
\hline N 3 & $\begin{array}{l}\text { Fake paper highlights predatory } \\
\text { publishers }\end{array}$ & ABC (AUS) & $\begin{array}{l}\text { http://www.abc.net.au/science/articles/2013/10/04/ } \\
\text { 3862443.htm }\end{array}$ \\
\hline $\mathrm{N} 4$ & $\begin{array}{l}\text { Fake cancer study spotlights bogus } \\
\text { science journals }\end{array}$ & National Geographic Daily News & $\begin{array}{l}\text { http://news.nationalgeographic.com/news/2013/10/ } \\
\text { 131003-bohannon-science-spoof-open-access-peer- } \\
\text { review-cancer/ }\end{array}$ \\
\hline N 5 & Science's Sokal moment & The Economist & $\begin{array}{l}\text { http://www.economist.com/news/science-and- } \\
\text { technology/21587197-it-seems-dangerously-easy- } \\
\text { get-scientific-nonsense-published-sciences-sokal }\end{array}$ \\
\hline N 6 & $\begin{array}{l}\text { Fake science paper spoofs hundreds of } \\
\text { almost fake journals }\end{array}$ & The Examiner & $\begin{array}{l}\text { http://www.examiner.com/article/fake-science-paper- } \\
\text { spoofs-hundreds-of-almost-fake-journals?cid=rss }\end{array}$ \\
\hline N 7 & $\begin{array}{l}\text { Inside Science Magazine's 'Sting' of } \\
\text { Open Access Journals }\end{array}$ & Motherboard-The Vice & $\begin{array}{l}\text { http://motherboard.vice.com/blog/inside-science- } \\
\text { magazines-sting-of-open-access-journals-1 }\end{array}$ \\
\hline N 8 & $\begin{array}{l}\text { The Good and the Bad of Open Access } \\
\text { Journals }\end{array}$ & Huffington Post & $\begin{array}{l}\text { http://www.huffingtonpost.com/a-townsend-peterson/ } \\
\text { the-good-and-the-bad-of-o_b_4068898.html }\end{array}$ \\
\hline N 9 & $\begin{array}{l}\text { Online medical journals accept fake } \\
\text { study: Could the public be hurt? }\end{array}$ & Whas11-ABC News (US) & $\begin{array}{l}\text { http://www.whas11.com/news/Online-medical- } \\
\text { journals-accept-fake-study-Could-the-public-be-hurt- } \\
\text { 227647001.html }\end{array}$ \\
\hline N 10 & $\begin{array}{l}\text { In Study, Open Access Science Journals } \\
\text { Accept Fake Paper }\end{array}$ & The Harvard Crimson & $\begin{array}{l}\text { http://www.thecrimson.com/article/2013/10/16/study- } \\
\text { science-journals-fake-research/ }\end{array}$ \\
\hline N 11 & Dubious journal fear stalks India & The Telegraph (India) & $\begin{array}{l}\text { http://www.telegraphindia.com/1131004/jsp/nation/ } \\
\text { story_17423175.jsp\#.Uk8lumSDSRs }\end{array}$ \\
\hline $\mathrm{N} 12$ & Science's Open Access challenge & UTSanDiego & $\begin{array}{l}\text { http://www.utsandiego.com/news/2013/oct/06/science- } \\
\text { open-access/ }\end{array}$ \\
\hline N 13 & Is Peer Review A Big Bad Joke? & Fast-Co.Exist & $\begin{array}{l}\text { http://www.fastcoexist.com/3019577/is-peer-review-a- } \\
\text { big-bad-joke }\end{array}$ \\
\hline $\mathrm{N} 14$ & $\begin{array}{l}\text { Despite flaws, Open Access is worth } \\
\text { the price }\end{array}$ & DailyTexanOnline & $\begin{array}{l}\text { http://www.dailytexanonline.com/opinion/2013/10/11/ } \\
\text { despite-flaws-open-access-is-worth-the-price }\end{array}$ \\
\hline N 15 & $\begin{array}{l}\text { Bogus science paper accepted by } \\
\text { dozens of journals }\end{array}$ & The Boston Globe & $\begin{array}{l}\text { http://www.bostonglobe.com/news/science/2013/10/03/ } \\
\text { bogus-science-paper-accepted-dozens-journals/ } \\
\text { QJ4h2ba7LAHk5PJcGdGkgM/story.html }\end{array}$ \\
\hline N 16 & $\begin{array}{l}\text { Hundreds of Open Access journals } \\
\text { accept fake science paper }\end{array}$ & The Guardian & $\begin{array}{l}\text { http://www.theguardian.com/higher-education-network/ } \\
\text { 2013/oct/04/open-access-journals-fake-paper }\end{array}$ \\
\hline N 17 & $\begin{array}{l}\text { Paper written as science hoax published } \\
\text { by } 157 \text { science journals }\end{array}$ & United Press International & $\begin{array}{l}\text { http://www.upi.com/Science_News/2013/10/03/Paper- } \\
\text { written-as-science-hoax-published-by-157-science- } \\
\text { journals/UPI-67611380846842/ }\end{array}$ \\
\hline
\end{tabular}

